EXTENDED REPORT

\title{
Prevalence and pattern of radiographic hand osteoarthritis and association with pain and disability (the Rotterdam study)
}

\author{
S Dahaghin, S M A Bierma-Zeinstra, A Z Ginai, H A P Pols, J M W Hazes, B W Koes

See end of article for authors' affiliations

Correspondence to Dr Saeede Dahaghin, Department of General Practice, Room Ff 325 Erasmus Medical Centre, PO Box 1738, 3000 DR Rotterdam, Netherlands; s_dahaghin@yahoo.com

Accepted

1 September 2004

Published Online First

16 September 2004

\begin{abstract}
Objective: To investigate the prevalence and pattern of radiographic osteoarthritis (ROA) of the hand joints and its association with self reported hand pain and disability.

Methods: Baseline data on a population based study (age $\geqslant 55$ years) were used $(n=3906)$. Hand ROA was defined as the presence of Kellgren-Lawrence grade $\geqslant 2$ radiological changes in two of three groups of hand joints in each hand. The presence of hand pain during the previous month was defined as hand pain. The health assessment questionnaire was used to measure hand disability.

Results: $67 \%$ of the women and $54.8 \%$ of the men had ROA in at least one hand joint. DIP joints were affected in $47.3 \%$ of participants, thumb base in $35.8 \%$, PIP joints in $18.2 \%$, and MCP joints in $8.2 \%$ (right or left hand). ROA of other joint groups (right hand) co-occurred in $56 \%$ of DIP involvement, $88 \%$ of PIP involvement, $86 \%$ of MCP involvement, and $65 \%$ of thumb base involvement. Hand pain showed an odds ratio of 1.9 (1.5 to 2.4) with the ROA of the hand (right). Hand disability showed an odds ratio of 1.5 (1.1 to 2.1) with ROA of the hand (right or left).

Conclusions: Hand ROA is common in the elderly, especially in women. Co-occurrence of ROA in different joint groups of the hand is more common than single joint disease. There is a modest to weak association between ROA of the hand and hand pain/disability, varying with the site of involvement.
\end{abstract}

\section{METHODS}

\section{Study population}

For this study we used cross sectional baseline data from the Rotterdam study, a population based cohort. The medical ethics committee of the Erasmus Medical Centre approved the study, and written informed consent was obtained from all participants.

The baseline measurements were conducted between 1990 and 1993. The complete study design has been described previously. ${ }^{11}$ All inhabitants of a suburb of Rotterdam aged 55 years and older were invited to participate. In all, 7983 participants were examined (a response rate of $78 \%$ ). At baseline, trained interviewers undertook an extensive home interview on demographic characteristics, medical history, risks factors for chronic diseases, and therapeutic drug use. Radiographs were taken at the research centre at baseline. For feasibility reasons we scored hand radiographs for ROA on only 3906 of the participants, including all those who were available for follow up six years later $(\mathrm{n}=3585)$.

\section{Radiographic scoring}

Two trained assessors (S Dahaghin and U Cimen), who were blinded to the clinical and demographic data, scored standard anteroposterior radiographs of both hands in 2002. Radiographs were scored for six individual radiographic features of osteoarthritis in the five distal interphalangeal (DIP) joints, four proximal interphalangeal (PIP) joints, five metacarpophalangeal (MCP) joints, the first carpometacarpal joint (CMCl), and the trapezioscaphoid joint (TS). Osteophytes were differentiated into three grades (small, moderate, large), while joint space narrowing, sclerosis, cysts, lateral deformity, and cortical collapse were scored as either present or absent. Lateral deformity was defined as malalignment of at least $15^{\circ}$ (modified Kallman score). ${ }^{12}$ Each joint was graded for overall ROA using a modified KellgrenLawrence (K-L) grade scaled from 0 to 4 (appendix 1). ${ }^{13}$ ROA for each joint was defined as a K-L grade of $\geqslant 2$. DIP, PIP,

Abbreviations: $\mathrm{CMCl} / \mathrm{TS}$, first carpometacarpal and trapezioscaphoid joint; DIP, distal interphalangeal joint; K-L, Kellgren-Lawrence radiological grade; $M C P$, metacarpophalangeal joint; PIP, proximal interphalangeal joint; ROA, radiographic osteoarthritis 


\begin{tabular}{|c|c|c|c|}
\hline \multicolumn{4}{|l|}{ Characteristic } \\
\hline \multirow[t]{2}{*}{$\begin{array}{l}\text { Female (\%) } \\
\text { Age (years) (mean (SD)) } \\
+ \text { Hand disability (\%) } \\
+ \text { +Overall disability index (\%) }\end{array}$} & \multicolumn{3}{|l|}{$\begin{array}{l}58.3 \\
66.6(7.3) \\
5.8 \\
20.2\end{array}$} \\
\hline & Right/left & Right & Left \\
\hline $\begin{array}{l}\text { *ROA of DIP joints (\%) } \\
{ }^{*} \text { ROA of PIP joints (\%) } \\
{ }^{*} \text { ROA of } M C P \text { joints }(\%) \\
{ }^{*} \text { ROA of CMCI/TS }(\%) \\
\text { tHand ROA }(\%) \\
\text { Hand pain }(\%)\end{array}$ & $\begin{array}{l}47.3 \\
18.2 \\
8.2 \\
35.8 \\
28.3 \\
16.8\end{array}$ & $\begin{array}{l}38.6 \\
13.4 \\
6.1 \\
25.8 \\
21.5 \\
14.2\end{array}$ & $\begin{array}{l}34.8 \\
11.6 \\
4.4 \\
30.2 \\
20.6 \\
13.5\end{array}$ \\
\hline \multicolumn{4}{|c|}{$\begin{array}{l}\text { +Hand disability: mean score of } 0.5 \text { or more of various components } \\
\text { composed of eight questions related to hand function on the Stanford } \\
\text { health assessment questionnaire (HAQ). } \\
++ \text { Overall disability index: mean score of } 0.5 \text { or more on HAQ index } \\
\text { (scored } 0 \text { to } 3 \text { ). } \\
\text { "ROA: presence of } K-L \geqslant 2 \text { in at least one joint of the group. } \\
\text { tHand ROA: presence of } K-L \geqslant 2 \text { in two of three groups (DIP, PIP, CMCl/ } \\
\text { TS). } \\
C M C 1 / T S \text {, first carpometacarpal plus trapezioscaphoid (base of thumb); } \\
\text { DIP, distal interphalangeal; K-L, Kellgren-Lawrence radiological grade; } \\
\text { MCP, metacarpophalangeal; PIP, proximal interphalangeal; ROA, } \\
\text { radiographic osteoarthritis. }\end{array}$} \\
\hline
\end{tabular}

MCP, and CMCl/TS joint groups were defined as positive if at least one joint of the group had a K-L grade of $\geqslant 2$. Hand ROA was defined as the presence of a K-L grade of $\geqslant 2$ in two of three groups of hand joints (DIP, PIP, and CMCl/TS) of each hand. The same definition was used for the cut off point K-L $\geqslant 3$ or $\mathrm{K}-\mathrm{L}=4$.

To investigate the reliability of the scoring, the two assessors both scored a random subset of 205 radiographs independently. The interobserver reliability for $\mathrm{K}-\mathrm{L} \geqslant 2$ as a dichotomous variable expressed by the $\kappa$ statistic was as follows: DIP joints, 0.60; PIP joints, 0.61; MCP joints, 0.63; and CMC1/TS (base of thumb), 0.74 .

\section{Hand pain}

The following questions were asked during the home interview:

- Did you have pain on the right (left) hand during the last month?

- How long have you had the pain?

The answer to the second question ranged from less than one month to more than five years.

\section{Hand disability}

Stanford health assessment questionnaire (HAQ) was used to assess disability. Eight questions on the HAQ concerning hand function were used to assess hand disability (appendix 2 ). Each question scored from "no difficulty" (0) to "unable to do" (3). Of the components with more than one question related to the hand function, the highest score was considered (as in the original HAQ). ${ }^{14}{ }^{15}$ Dependence on equipment or physical assistance was ignored; this represents residual disability after compensatory efforts. The scores were averaged into an overall hand disability score on a scale from 0 (no hand disability) to 3 (hand severely disabled). A mean score of $\geqslant 0.5$ was considered to mean a moderate to severe hand disability.

\section{Data analysis}

Point prevalence of ROA was calculated for each joint, for the joint groups, and for the whole hand. A rectangle diagram (Venn diagram with four variables) was used to show the distribution of ROA in the four hand joint groups.

Univariate and multivariate logistic regression analysis was used to evaluate the strength of the association of ROA in the different hand joint groups in each hand and also to examine associations between ROA and hand pain and/or disability. The associations are presented as odds ratios (OR) with 95\% confidence intervals (CI) and were adjusted for age and sex. All analyses were carried out at the level of the person. The association between ROA and hand pain was evaluated for each hand separately, while the association with hand

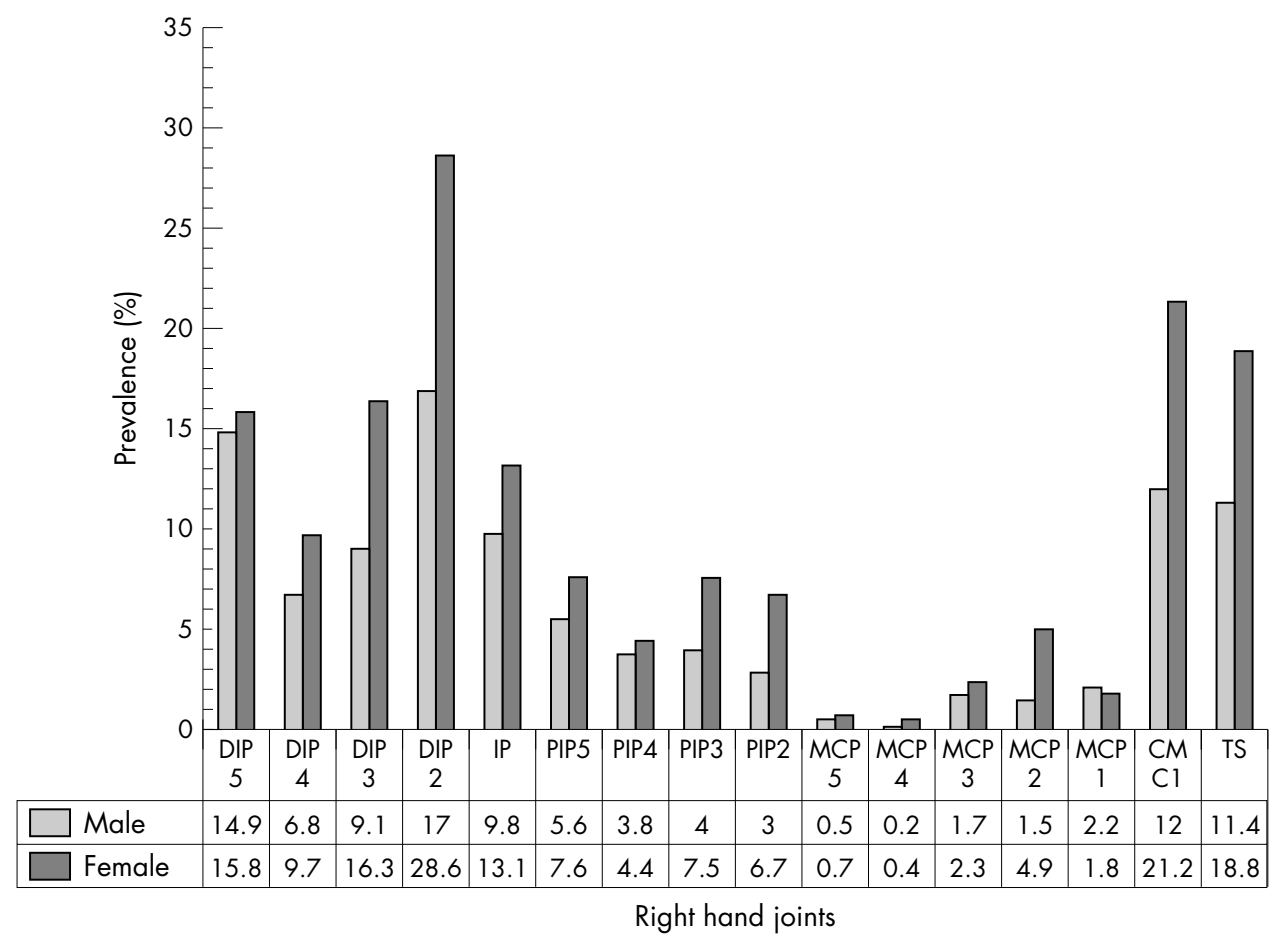

Figure 1 Point prevalence of radiographic osteoarthritis (Kellgren-Lawrence radiological grade $\geqslant 2$ ) in the hand joints of men and women ( $\mathrm{n}=3906$ ). 
disability was evaluated for the presence of ROA in either the right or the left hand as well as for ROA of the dominant hand. The association with hand pain and/or disability was also examined in relation to the number of joints with ROA (as a continuous variable) and for the more severe forms of ROA ( $K-\mathrm{L} \geqslant 3$ or $\mathrm{K}-\mathrm{L}=4$ ).

The SPSS (version 10) program was used for all analyses. The Span program was used to generate rectangle diagrams. ${ }^{16}$

\section{RESULTS}

In all, we evaluated 3906 participants (53.8\% female, $46.2 \%$ male), of mean age 66.6 years (table 1 ).

\section{Prevalence and pattern of ROA}

In all, $61.7 \%$ of our study population had K-L $\geqslant 2$ in at least one of the joints of the hand (67\% of the women and $54.8 \%$ of the men). DIP joints had the highest frequency $(47.3 \%)$, followed by CMCl/TS joints (35.8\%), PIP joints (18.2\%), and MCP joints $(8.2 \%)$ of the right or left hand.

ROA in the separate DIP joints (right hand) occurred in $6.8-17 \%$ of men and in $9.7-28.6 \%$ of women. The ranges were $3.0 \%$ to $5.6 \%$ and $4.4 \%$ to $7.6 \%$ in the PIP joints, $0.2 \%$ to $2.2 \%$ and $0.4 \%$ to $4.9 \%$ in the MCP joints, and $11.4 \%$ to $12.0 \%$ and $18.8 \%$ to $21.2 \%$ in the CMCl/TS joints for men and women, respectively (fig 1 ).

Except for DIP 2 (right $=23.5 \%$, left $=16.8 \%), \quad$ CMCl (right $=17.2 \%, \quad$ left $=21.3 \%)$, and TS $\quad($ right $=15.6 \%$, left $=17.6 \%$ ), the other hand joints showed almost the same frequency in the right and left hands.

Hand ROA was present in $21.5 \%$ of right hands and 20.6 of left hands. The prevalence of ROA increased with age up to 84 years, but decreased in the group aged 85 years and older (fig 2).

Use of a rectangle diagram showed that ROA in one joint group more often co-occurred with ROA in other joint groups in women than in men: DIP joints, 61\% (women) $v 47 \%$ (men); PIP joints, 91\% v 82\%; MCP joints, 91\% v 77\%; CMCl/ TS joints, $68 \% \vee 59 \%$ (all in the right hand, fig 3). Evaluating the strength of the relations, the PIP joints and the MCP joints had the highest odds ratios with ROA of the other joint groups of the right hand ( $\mathrm{OR}=9.1(95 \% \mathrm{CI}, 6.8$ to 12.4$)$ and $\mathrm{OR}=5.4$ (3.6 to 8.0 ), respectively). CMC1/TS joints showed the lowest association with other joint groups of the right hand $(\mathrm{OR}=3.1(2.6$ to 3.6$))$ (table 2$)$. The left hand showed similar results.

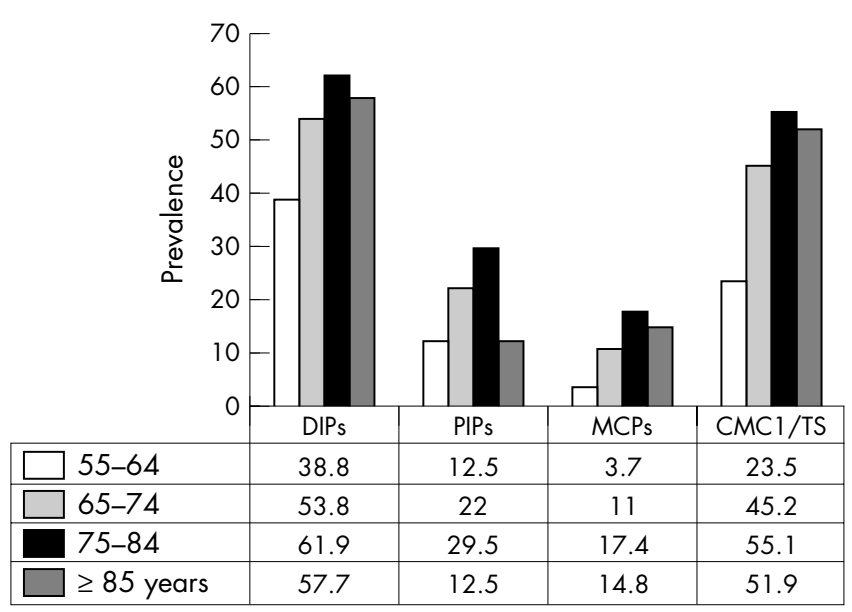

Figure 2 Age specific point prevalence (\%) of osteoarthritis in hand joint groups (right/left).

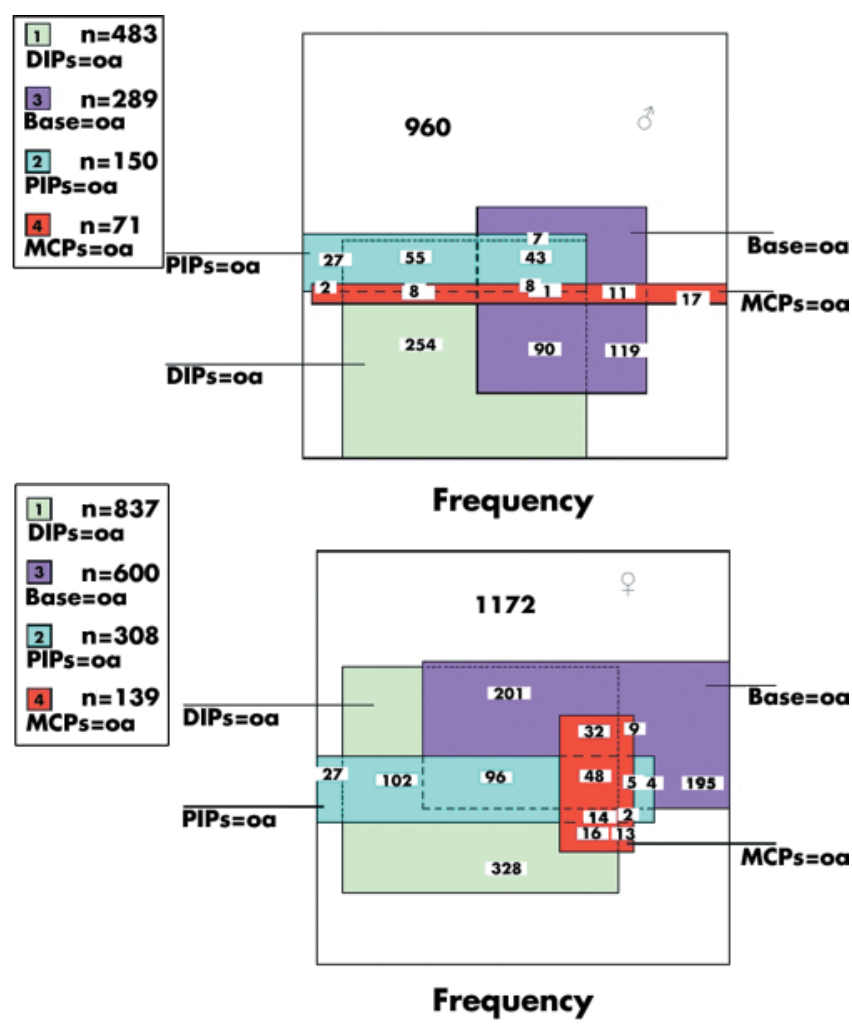

Figure 3 Rectangle diagram of radiographic osteoarthritis in the hand joint groups $(n=3906)$. The coloured rectangles represent osteoarthritis (oa) of Kellgren-Lawrence radiological grade $\geqslant 2$ in at least one joint of the group (DIP, PIP, MCP, base) in the right hand for men (top panel) and women (bottom panel). Base, first carpometacarpal and trapezioscaphoid joint (thumb base); DIP, distal interphalangeal joint; MCP, metacarpophalangeal joint; PIP, proximal interphalangeal joint.

\section{ROA and hand pain}

Prevalence of hand pain (right) was 14.2\%; 97\% of the participants suffered from this for longer than one month. Table 3 shows the association between hand pain and ROA in the joint groups of the right hand, the strongest being with the CMC1/TS. Right hand pain showed an association with ROA of the related hand $(\mathrm{OR}=1.9(95 \% \mathrm{CI}, 1.5$ to 2.4$))$. With the cut off point at $\mathrm{K}-\mathrm{L} \geqslant 3$ the association was nearly the same $(\mathrm{OR}=1.8$ ( 1.3 to 2.5$))$, but when the cut off point was increased to $\mathrm{K}-\mathrm{L}=4$, there was a stronger association with pain in the right hand $(\mathrm{OR}=3.6$ (2.2 to 5.8)). Increasing the number of joints with ROA produced a greater association with pain $(\mathrm{OR}=1.1$ (1.1 to 1.2$)$, right hand). Generalised hand osteoarthritis (ROA of all four joint groups of the right hand) showed an increased association with hand pain $(\mathrm{OR}=2.7$ (1.4 to 5.2$))$. The associations of hand pain and ROA in the left hand were similar but are not presented here.

\section{ROA and hand disability}

The prevalence of hand disability was $5.8 \%$. The presence of hand ROA (right/left) showed an association with hand disability $(\mathrm{OR}=1.5 \quad(1.1$ to 2.1$))$. Specification to the dominant hand gave nearly the same results. Table 4 shows the association between hand disability and ROA (right/left) differentiated for hand joint group; the association was only significant for the MCP joints ( $\mathrm{OR}=2.0$ (1.3 to 3.0)). The association of ROA of the base of the thumb became significant when the analysis was specified to the dominant hand. However, MCP joints of the dominant hand showed odds ratios similar to the base of the thumb for hand disability. 


\begin{tabular}{|c|c|c|c|c|}
\hline & \multicolumn{4}{|l|}{ Right hand } \\
\hline & PIP & MCP & $\mathrm{CMCl} / \mathrm{TS}$ & Any other joint group \\
\hline $\begin{array}{l}\text { DIP } \\
\text { PIP } \\
\text { MCP } \\
\mathrm{CMC1} / \mathrm{TS}\end{array}$ & 9.1 (7.1 to 11.7$)$ & $\begin{array}{l}3.9(2.9 \text { to } 5.5) \\
4.7(3.5 \text { to } 6.4)\end{array}$ & $\begin{array}{l}2.9(2.5 \text { to } 3.4) \\
2.8(2.3 \text { to } 3.5) \\
3.8(2.9 \text { to } 5.2)\end{array}$ & $\begin{array}{l}4.4(3.7 \text { to } 5.0) \\
9.1(6.8 \text { to } 12.4) \\
5.4(3.6 \text { to } 8.0) \\
3.1(2.6 \text { to } 3.6)\end{array}$ \\
\hline
\end{tabular}

Using the cut off points $\mathrm{K}-\mathrm{L} \geqslant 3$ and $\mathrm{K}-\mathrm{L}=4$ (right/left) showed nearly the same association with hand disability $(\mathrm{OR}=1.6$ ( 1.1 to 2.5$)$ and $\mathrm{OR}=1.6$ (0.9 to 2.9$)$, respectively) . An increase in the number of hand joints with ROA showed a borderline significant association with hand disability. This association increased to a significant level when the number of joints with ROA in only the dominant hand was analysed in relation to hand disability $(\mathrm{OR}=1.1 \quad(1.0$ to 1.2$))$. Generalised hand osteoarthritis (ROA in all four hand joint groups) also showed a stronger association with hand disability $(\mathrm{OR}=2.7(1.3$ to 6.0$))$.

\section{DISCUSSION}

The results of our study confirm that hand ROA is a common disease in the elderly, especially in women. It is more likely to occur in several different hand joint groups simultaneously than in single joints, the latter being more prevalent in women than in men. More than $80 \%$ of ROA affecting the PIP and MCP joints co-occurred with the other hand joint groups. We confirmed a modest association between ROA and hand pain, the strongest relation being with involvement of the base of the thumb. Hand disability showed a rather weak association with ROA, the strongest relation being with the MCP joints and the base of the thumb.

As the hand joints are small and the features of osteoarthritis often difficult to define, interpreting the radiographs of these joints is challenging. However, our interobserver reliability was good and similar to the results of other studies. ${ }^{917}$ The predominance given to osteophytes in the original Kellgren-Lawrence grading scheme has been discussed previously. ${ }^{18}$ In the present study we used the modified definition which defines grade 3 ROA as a diminution in joint space regardless of whether or not there are osteophytes. This eliminates the predominance given to the osteophyte and thus probably provides more valid results. The definition of hand osteoarthritis (ROA in two of three hand joint groups) which we used, reported by Hirsch et al, ${ }^{17}$

Table 3 Association of hand pain with radiographic osteoarthritis in the hand joint groups (right hand)

\begin{tabular}{lll}
\hline Joint group & Univariate & Multivariate \\
\hline${ }^{*} \mathrm{DIP}$ & $1.5(1.2$ to 1.8$)$ & $1.1(0.9$ to 1.4$)$ \\
${ }^{*} \mathrm{PIP}$ & $1.8(1.4$ to 2.3$)$ & $1.4(1.1$ to 1.9$)$ \\
${ }^{*} \mathrm{MCP}$ & $1.6(1.1$ to 2.3$)$ & $1.2(0.8$ to 1.7$)$ \\
${ }^{*} \mathrm{CMCl} / \mathrm{TS}$ & $2.0(1.6$ to 2.4$)$ & $1.7(1.4$ to 2.2$)$ \\
\hline
\end{tabular}

Values are odds ratios ( $95 \%$ confidence intervals) adjusted for age and sex.

*Presence of Kellgren-Lawrence radiological grade $\geqslant 2$ in at least one joint of the group.

$\mathrm{CMCl}$ /TS, first carpometacarpal and trapezioscaphoid joint (base of thumb); DIP, distal interphalangeal joint; $M C P$, metacarpophalangeal joint; PIP, proximal interphalangeal joint. does not include the MCP joints. To evaluate whether including the MCP joints in the definition would change the association with hand pain or disability we also tested an alternative definition of hand ROA that included the MCP joints (ROA in two of four hand joint groups in each hand). With this alternative definition the results were the same.

In our study, over $55 \%$ of the participants had ROA in at least one hand joint. This means that cartilage degeneration or subchondral bone reaction is present in at least one joint of the hand in more than half the open population aged 55 years and over. This high frequency of ROA, increasing with age and more frequent in the women, confirms previous findings. ${ }^{4}{ }^{12}{ }^{19}$ Van Saase ${ }^{4}$ reported a slight decrease in the prevalence of ROA in very old people, which was confirmed in our study in people aged 85 years and over. However, only 47 participants of our study population (1.2\%) reached this age, which may have produced an unstable estimate in this group. Considering that osteoarthritis is a chronic disease, another possible explanation is the selection of healthy survivors or a lower response rate of disabled persons.

The order of involvement of the hand joint groups in our study was also comparable with other findings. DIP joints and the base of the thumb were involved most often, followed by the PIP joints. This was also reported by Kellgren et al and Egger et al. ${ }^{2021}$ The MCP joints had the lowest frequency in our population, in accordance with findings of Chaisson et al but in contrast to van Saase et al, who reported a higher prevalence of ROA in MCP than in PIP joints. ${ }^{4}$ Chaisson et al also reported this inconsistency. ${ }^{22}$

For the first time, we have visualised the pattern of ROA of the hand joint groups occurring solely or co-occurring with other joint groups in a rectangle diagram. This shows that the PIP and MCP joints are more affected concurrently with the other joint groups and are rarely affected alone. This finding was confirmed by logistic regression analysis. The base of the thumb had the lowest odds ratio with the other joint groups. This supports the view that systemic factors play a more

Table 4 Association of hand disability with radiographic osteoarthritis in the hand joint groups

\begin{tabular}{lll}
\hline Joint group & Univariate & Multivariate \\
\hline${ }^{*} \mathrm{DIP}$ & $1.3(0.9$ to 1.8$)$ & $1.2(0.8$ to 1.7$)$ \\
${ }^{*} \mathrm{PIP}$ & $1.1(0.8$ to 1.7$)$ & $0.9(0.6$ to 1.4$)$ \\
${ }^{*} \mathrm{MCP}$ & $2.0(1.3$ to 3.0$)$ & $1.8(1.2$ to 2.9$)$ \\
${ }^{*} \mathrm{CMCl} / \mathrm{TS}$ & $1.3(1.0$ to 1.9$)$ & $1.2(0.8$ to 1.7$)$ \\
\hline
\end{tabular}

Values are odds ratios ( $95 \%$ confidence intervals) adjusted for age and sex.

Presence of Kellgren-Lawrence radiological grade $\geqslant 2$ in at least one joint of the group in the right/left hand.

$\mathrm{CMCl}$ /TS, first carpometacarpal and trapezioscaphoid joint (base of thumb); DIP, distal interphalangeal joint; $M C P$, metacarpophalangeal joint; PIP, proximal interphalangeal joint. 
important role than physical factors in ROA of the PIP and MCP joints, but local mechanical factors may play a greater role in ROA of the base of the thumb.

With regard to the association between a structural marker of osteoarthritis and its clinical impact, the presence of hand ROA shows a modest to weak association with clinical symptoms such as hand pain and/or disability, as reported previously. ${ }^{10}$ Surprisingly, our analysis in an open population gave a similar association of ROA with hand pain or disability to that reported by Jones et $a l^{10}$ who analysed a group of subjects with a diagnosis of hand osteoarthritis. In addition, we found a dose-response relation with hand pain, which increased with the number of joints affected by ROA, with generalised hand ROA (with all four hand joint group involved), and with the severe form of ROA (KellgrenLawrence grade 4). However, only generalised hand ROA, and not the severity of Kellgren-Lawrence grade, showed a significant increase in the association with hand disability.

We examined the relation between hand pain and ROA of the different hand joint groups and showed that ROA of the base of the thumb had the strongest association with hand pain. This supports the hypothesis that ROA of the base of the thumb has a greater impact on pain than the other hand joint groups. ROA of the base of the thumb (right or left side) was less associated with hand disability than ROA of the MCP joints. However, ROA of the base of the thumb on the dominant hand had a significant association with hand disability, similar to that of the MCP group in the dominant hand. We initially thought that the relation with MCP joint disease might reflect the presence of another inflammatory disorder such as rheumatoid arthritis. However, ROA of the MCP joints was concurrent in more than $80 \%$ of cases with ROA of the other hand joint groups, while it is rare in rheumatoid arthritis. Thus the result suggests that ROA at the MCP joints is more disabling than at other sites, or indicates again that a more generalised form of hand ROA is more disabling.

This study has several potential limitations. First, it was primarily designed as a study of determinants and prognosis of chronic diseases in elderly people and not specifically for hand disease. Thus we did not have data on the exact location of hand pain or a pain severity measure. Second, there was some selection bias in our study population compared with the total population of the Rotterdam study. We scored radiographs of 3906 participants including all those available for follow up six years later. Our study population was younger, had a smaller proportion of women, and was less disabled than the total population at baseline. To examine whether the results of our study can be generalised to the overall Rotterdam population, we estimated the point prevalence of hand ROA in the whole of the Rotterdam study. Adjusted for the different age groups this resulted in an almost 3\% higher estimate. The estimate was almost $2 \%$ higher when adjusted for the severity of general disability. Thus the point prevalence of ROA shown in our study is probably somewhat of an underestimate. However, the prevalence of hand pain was the same for both populations. The association with hand pain and/or disability might also be underestimated in our population.

\section{Conclusions}

We present extensive data on the prevalence of ROA of hand joint groups in a large open population of elderly people of both sexes which will add to the existing knowledge of this disorder. Our study also showed that the PIP and MCP joint groups were often affected concurrently with the other joint groups and rarely alone. Of the separate hand joint groups, ROA of the thumb base was the main determinant of hand pain, followed by the PIP joints. Although the DIP joints were the most affected joints in the hand, ROA in this joint group seems clinically unimportant. ROA of the MCP joints and the base of the thumb were both associated with hand disability.

\section{ACKNOWLEDGEMENTS}

We thank Mrs R Bernsen for statistical analysis and Mr U Cimen for scoring the radiographs, and $\mathrm{F}$ van Rooij, E van der Heijden, R Vermeeren, and L Verwey for collecting the data. We also thank the general practitioners, pharmacists, and the many field workers at the research centre in Ommoord, and of course all the participants.

\section{Authors' affiliations}

S Dahaghin, S M A Bierma-Zeinstra, B W Koes, Department of General Practice, Erasmus Medical Centre, Rotterdam, Netherlands

H A P Pols, J M W Hazes, Department of Epidemiology and Biostatistics, Erasmus Medical Centre

A Z Ginai, Department of Radiology, Erasmus Medical Centre

\section{APPENDIX 1}

\section{DEFINITION OF THE KELLGREN-LAWRENCE RADIOGRAPHIC GRADES}

Grade 0, none: no features of osteoarthritis

Grade 1, doubtful: minute osteophyte, doubtful significance Grade 2, minimal: definite osteophyte, unimpaired joint space

Grade 3, moderate: diminution of joint space

Grade 4, severe: joint space impaired with sclerosis of subchondral bone

\section{APPENDIX 2}

\section{QUESTIONS ON THE HEALTH ASSESSMENT QUESTIONNAIRE (HAQ) USED FOR THE HAND DISABILITY INDEX}

Are you able to?

- Dress yourself, including handling of closures?

- Comb your hair or do your own make-up?

- Turn taps on and off?

- Cut your meat, and lift a full cup or glass to your mouth?

- Open a new milk carton?

- Open car doors?

- Hold a pen or a pencil?

- Open jars which have been opened previously?

\section{REFERENCES}

1 Felson DT. Epidemiology of hip and knee osteoarthritis. Epidemiol Rev 1988; 10:1-28.

2 March LM, Bachmeier CJ. Economics of osteoarthritis: a global perspective. Baillieres Clin Rheumatol 1997;1 1:817-34.

3 Carmona L, Ballina J, Gabriel R, Laffon A. The burden of musculoskeletal diseases in the general population of Spain: results from a national survey. Ann Rheum Dis 2001;60:1040-5.

4 van Saase JL, van Romunde LK, Cats A, Vandenbroucke JP, Valkenburg HA. Epidemiology of osteoarthritis: Zoetermeer survey. Comparison of radiological osteoarthritis in a Dutch population with that in 10 other populations. Ann Rheum Dis 1989;48:271-80

5 Niu J, Zhang Y, LaValley M, Chaisson CE, Aliabadi P, Felson DT. Symmetry and clustering of symptomatic hand osteoarthritis in elderly men and women: the Framingham Study. Rheumatology (Oxford) 2003:42:343-8.

6 Peat G, Croft P, Hay E. Clinical assessment of the osteoarthritis patient. Best Pract Res Clin Rheumatol 2001;15:527-44.

7 Felson DT, Lawrence RC, Dieppe PA, Hirsch R, Helmick CG, Jordan JM, et al. Osteoarthritis: new insights. Part 1. The disease and its risk factors. Ann Intern Med 2000;133:635-46.

8 Dieppe P. Management of hip osteoarthritis. BMJ 1995;311:853-7.

9 Zhang Y, Niu J, Kelly-Hayes M, Chaisson CE, Aliabadi P, Felson DT Prevalence of symptomatic hand osteoarthritis and its impact on functional status among the elderly: the Framingham Study. Am J Epidemiol 2002; 156:1021-7. 
10 Jones G, Cooley HM, Bellamy N. A cross-sectional study of the association between Heberden nodes, radiographic osteoarthritis of the hands, grip strength, disability and pain. Osteoarthritis Cartilage $2001 ; 9: 606-11$.

11 Hofman A, Grobbee DE, de Jong PT, van den Ouweland FA. Determinants of disease and disability in the elderly: the Rotterdam Elderly Study. Eur J Epidemiol 1991;7:403-22.

12 Kallman DA, Wigley FM, Scott WW, Hochberg MC, Tobin JD. The longitudinal course of hand osteoarthritis in a male population. Arthritis Rheum 1990;33:1323-32.

13 Cooper C, Egger P, Coggon D, Hart DJ, Masud T, Cicuttini F, et al. Generalized osteoarthritis in women: pattern of joint involvement and approaches to definition for epidemiological studies. J Rheumatol 1996;23: 1938-42.

14 Bruce B, Fries JF. The Stanford health assessment questionnaire: dimensions and practical applications. Health Qual Life Outcomes 2003;1:20.

15 Fries JF, Spitz PW, Young DY. The dimensions of health outcomes: the health assessment questionnaire, disability and pain scales. J Rheumatol 1982;9:789-93
16 Marshall RJ. Displaying clinical data relationships using scaled rectangle diagrams. Stat Med 2001;20:1077-88.

17 Hirsch R, Lethbridge-Cejku M, Hanson R, Scott WW Jr, Reichle R, Plato CC, et al. Familial aggregation of osteoarthritis: data from the Baltimore Longitudinal Study on Aging. Arthritis Rheum 1998:41:227-32.

18 Hart DJ, Spector TD. Radiographic criteria for epidemiologic studies of osteoarthritis. J Rheumatol Suppl 1995:43:46-8.

19 Kalichman L, Cohen Z, Kobyliansky E, Livshits G. Patterns of joint distribution in hand osteoarthritis: contribution of age, sex, and handedness. Am J Human Biol 2004; 16:125-34.

20 Kellgren JH, Moore R. Generalized osteoarthritis and Heberden's nodes. BMJ 1952;i:181-7.

21 Egger P, Cooper C, Hart DJ, Doyle DV, Coggon D, Spector TD. Patterns of joint involvement in osteoarthritis of the hand: the Chingford Study. $J$ Rheumatol 1995;22:1509-13.

22 Chaisson CE, Zhang Y, McAlindon TE, Hannan MT, Aliabadi P, Naimark A, et al. Radiographic hand osteoarthritis: incidence, patterns, and influence of preexisting disease in a population based sample. J Rheumatol 1997:24:1337-43.

\section{bmjupdates+}

bmjupdates+ is a unique and free alerting service, designed to keep you up to date with the medical literature that is truly important to your practice. bmjupdates+ will alert you to important new research and will provide you with the best new evidence concerning important advances in health care, tailored to your medical interests and time demands.

Where does the information come from?

bmjupdates+ applies an expert critical appraisal filter to over 100 top medical journals A panel of over 2000 physicians find the few 'must read' studies for each area of clinical interest

Sign up to receive your tailored email alerts, searching access and more...

www.bmjupdates.com 


\section{PostScript}

\section{MATTERS ARISING}

Are autoantibodies against a 25mer synthetic peptide of $M 3$ muscarinic acetylcholine receptor a new diagnostic marker for Sjögren's syndrome?

We read with great interest the article by Naito and colleagues, ${ }^{1}$ who recently proposed the autoantibodies against M3 muscarinic acetylcholine receptor (anti-M3R) as a new diagnostic marker for patients with Sjögren's syndrome (SS).

We have been studying anti-M3R recently ${ }^{2}$ and reviewed some theoretical aspects. ${ }^{3}$ The results of our work with the same 25-mer synthetic peptide (K-R-T-V-P-P-G-E-C-F-I-QF-L-S-E-P-T-I-T-F-G-T-A-I) as used by Naito et al showed a similar prevalence of anti-M3 in patients with SS (table 1). Nevertheless, we did not draw the same conclusions and could not agree with the statement that antibodies against the 25-mer synthetic peptide might be a new diagnostic marker for SS.

We believe that the authors should mention a misleading fact in the article by Bacman et al, ${ }^{4}$ which was discussed by Cavill et al and Dawson et al ${ }^{5}{ }^{6}$-namely, the sequence of 25-mer synthetic peptide used by Bacman et al was in fact the amino acid sequence from the second extracellular loop of M4 muscarinic acetylcholine receptor. Neither of the two groups were able to detect the activity of anti-M3R with conventional immunological approaches. Furthermore, Gao et al constructed a CHO cell line expressing the human M3R gene and found positive anti-M3R antibodies in 9/11 patients with SS and in none of 11 healthy controls.

The enzyme linked immunosorbent assay (ELISA) used by Naito et al was somewhat similar to our procedure. In our ELISA, Costar medium binding microtitre plates were coated with the same 25-mer peptide in absolute ethanol $(10 \mathrm{mg} / \mathrm{l})$, and incubated at $4{ }^{\circ} \mathrm{C}$ for at least 3 hours. Serum samples were first diluted $1: 100$ in $1 \%$ bovine serum albumin (BSA) phosphate buffered saline (PBS) (Naito et al 1:50 in 5\% BSA/PBS) and incubated for 1 hour at room temperature (Naito et al for 2 hours at $37^{\circ} \mathrm{C}$ ). Optical density values of anti-M3R were not normally distributed in any of our tested groups. Therefore, the cut off value was estimated at the 95th centile of 349 controls. Neither sensitivity nor specificity of the ELISA

\section{Rapid response}

If you have a burning desire to respond to a paper published in the Annals of the Rheumatic Diseases, why not make use of our "rapid response" option?

Log on to our website (www. annrheumdis.com), find the paper that interests you, and send your response via email by clicking on the "eletters" option in the box at the top right hand corner.

Providing it isn't libellous or obscene, it will be posted within seven days. You can retrieve it by clicking on "read eletters" on our homepage.

The editor will decide as before whether also to publish it in a future paper issue.

for SS was improved by binding the synthetic peptide to BSA by a cross linker $(\mathrm{N}$ $(\gamma$-maleimidobutyryloxy)succinimide ester; Pierce).

In conclusion, it seems that the 25-mer synthetic peptide used in routine immunological techniques ${ }^{25}$ does not disclose clinically relevant antibodies, suggesting that a short linear peptide does not depict an adequate epitope for the binding of antiM3R. Data presented by Gao et al, applying native M3R protein, seem far more promising, but they should be verified on a larger group of patients and controls.

P Žigon, B Božič, S Čučnik, B Rozman, $M$ Tomšič, T Kveder University Medical Centre, Department of Rheumatology, Ljubljana, Slovenia

Correspondence to: Ms T Kveder, University Medical Centre, Department of Rheumatology, Vodnikova 62, SI-1000 Ljubliana, Slovenia; tanja.kveder@kcli.si

\section{References}

1 Naito Y, Matsumoto I, Wakamatsu E, Goto D, Sugiyama T, Matsumura R, et al. Muscarinic acetylcholine receptor autoantibodies in patients with Sjögren's syndrome. Ann Rheum Dis 2005;64:510-11.

2 Žigon P, Cučnik S. Božič B, Rozman B, PlešivčnikNovljan $M$, Tomšič $M$, et al. Antibodies against 25-mer synthetic peptide of $M 3$ muscarinic acetylcholine receptor in patients with Siögren's syndrome and SLE. In, Conrad K, Sack U, eds. Autoantigens, autoantibodies, autoimmunity, Vol 4.Lengerich:Pabst Science Publishers, 2004:378-9.

3 Hočevar A, Tomšič M, Praprotnik S, Hojnik M, Kveder T, Rozman B. Parasympathetic nervous

Table 1 Anti-M3R antibodies in patients with Sjögren's syndrome (SS), systemic lupus erythematosus (SLE), and healthy controls (C)

\begin{tabular}{lllll}
\hline Abs (mOD) & $\begin{array}{l}\mathbf{C} \\
(\mathbf{n}=\mathbf{3 4 9})\end{array}$ & $\begin{array}{l}\text { SS† } \\
(\mathbf{n}=107)\end{array}$ & $\begin{array}{l}\text { SLE } \\
(\mathbf{n}=101)\end{array}$ & $\begin{array}{l}\text { pSS* } \\
(\mathbf{n}=\mathbf{7 5})\end{array}$ \\
\hline Average & 117 & 179 & 116 & 159 \\
Standard deviation & 122 & 266 & 120 & 220 \\
Median & 88 & 92 & 89 & 81 \\
Maximum & 1216 & 1755 & 872 & 1162 \\
Minimum & 2 & 7 & 2 & 7 \\
95th Centile & 285 & 635 & 355 & 572 \\
Number of positive sera & 17 & 16 & 6 & 11 \\
Percent of positive sera & 4.8 & 15.0 & 5.9 & 14.7 \\
\hline
\end{tabular}

*pSS, primary SS; †SS, primary + secondary SS. system dysfunction in primary Siögren's

syndrome. Ann Rheum Dis 2003;62:702-4

4 Bacman S, Berra A, Sterin-Borda L, Borda E.

Muscarinic acetylcholine receptor antibodies as a new marker of dry eye Siögren syndrome. Invest Ophthalmol Vis Sci 2001;42:321-7.

5 Cavill D, Waterman SA, Gordon TP. Failure to detect antibodies to extracellular loop peptides of the muscarinic M3 receptor in primary Sjögren's syndrome. J Rheumatol 2002;29:1342-4

6 Dawson LJ, Allison HE, Stanbury J, Fitzgerald D, Smith PM. Putative anti-muscarinic antibodies cannot be detected in patients with primary Sïgren's syndrome using conventional immunological approaches. Rheumatology (Oxford) 2004;43: 1488-95.

7 Gao J, Cha S, Jonsson R, Opalko J, Peck AB. Detection of anti-type 3 muscarinic acetylcholine receptor autoantibodies in the sera of Siögren's syndrome patients by use of a transfected cell line assay. Arthritis Rheum 2004;50:2615-21.

\section{Author's reply}

Dr Tanja Kveder et al point out two messages about our paper. ${ }^{1}$ Firstly, that our previous results ${ }^{1}$ are supported by their further experiments using the same 25-mer synthetic peptides. Secondly, they suggest that our statement that antibodies (Abs) to the 25mer synthetic peptide might be a new diagnostic marker for SS is open to criticism.

We agree with Dr Kveder's comments, in part, because we did not elucidate the function of the anti-25-mer synthetic peptide Abs using M3R transfected cells ${ }^{2}$ or HSG cell lines. However, Abs against the second extracellular portion of M3R are detected in a subgroup of patients with SS and the presence of this $\mathrm{Ab}$ is significantly associated with anti-SSB Ab. ${ }^{1}$ Therefore, we consider that anti-25-mer synthetic peptide Abs might be a new diagnostic marker in a subgroup of patients with SS. Of course, further experiments on the functional analysis using anti25-mer synthetic peptide Abs and anti-M3R protein Abs would be helpful to clarify the better diagnostic marker in patients with SS.

T Sumida

Department of Internal Medicine, University of Tsukuba, Tsukuba City, Japan; tsumida@ md.tsukuba.ac.jp

\section{References}

1 Naito Y, Matsumoto I, Wakamatsu E, Goto D, Sugiyama T, Matsumura R, et al. Muscarinic acetylcholine receptor autoantibodies in patients with Siögren's syndrome. Ann Rheum Dis 2005:64:510-11.

2 Gao J, Cha S, Jonsson R, Opalko J, Peck AB. Detection of anti-type 3 muscarinic acetylcholine receptor autoantibodies in the sera of Sjögren's patients by use of a transfected cell line assay. Arthritis Rheum 2004;50:2615-21.

\section{Short course prednisolone for adhesive capsulitis}

Adhesive capsulitis is a condition whose pathogenesis remains unclear and for which there is no consensus about the best medical treatment.

Writing recently in the Annals, Buchbinder and her colleagues examined 50 participants (24 receiving active treatment, 26 placebo) from community based rheumatology practices. ${ }^{1}$ The trial concluded that a "3 week course of $30 \mathrm{mg}$ prednisolone daily is of 
significant short term benefit in adhesive capsulitis, but benefits are not maintained beyond 6 weeks".

Although the authors were careful with their inclusion criteria, they failed to set a cut off point from the time of onset of pain and stiffness of the shoulder. Their subjects had a mean (SD) duration of symptoms of 25.3 (13.2) weeks. This indicates that some of the participants in this study had had a frozen shoulder for 38.6 weeks or approximately 9 months. The treatment period was limited to 3 weeks, regardless of the duration of symptoms. There were no other interventions.

Other reported studies have also included patients with long established adhesive capsulitis. ${ }^{23}$ The latter with a mean duration at presentation of 5.5 months before oral corticosteroids were used in a trial.

This study makes an important contribution to the subject, but the authors make the point that future research should evaluate different combinations of treatment and their optimal duration.

Based on my experience, I support this recommendation. I have reported the treatment of 30 patients with idiopathic frozen shoulder (IFS). The mean duration of symptoms before referral was 9 weeks. The treatment was with 1-3 intra-articular injections of betamethasone (Celestone Chronodose) followed by oral prednisone $15-20 \mathrm{mg}$ daily, initially for 2 weeks. A home exercise programme was advised. All 30 patients regained full range of movement of the affected shoulder with freedom from pain and without relapse. ${ }^{4}$

Future trials should incorporate a treatment group that includes a combination of oral and intra-articular corticosteroids Double blind trials are problematic given the generally poor outcome for untreated IFS. ${ }^{5}$ Patients with frozen shoulder with an onset greater than 16 weeks should be excluded from further trials.

IFS is a debilitating condition that is currently perceived as having a poor prognosis. Although it is not life threatening, it has a major impact on quality of life. It is therefore important that rheumatologists establish best practice for the management of this condition and educate other medical practitioners of the value of early, active treatment in achieving good outcomes.

W A Douglas

201 Wickham Terrace, Brisbane Qld 4000, Australia w_b_doug@bigpond.net.au

\section{References}

1 Buchbinder R, Hoving JL, Green S, Hall S, Forbes A, Nash P. Short course prednisolone for adhesive capsulitis (frozen shoulder or stiff painful shoulder); a randomised, double blind, placebo controlled trial. Ann Rheum Dis 2004;63:1460-9.

2 Blockey NJ, Wright JK, Kellgren JH. Oral cortisone therapy in periarthritis of the shoulder. BMJ 1954;1:1455-7.

3 Binder A, Hazelman BL, Parr G, Roberts S. A controlled study of oral prednisolone in frozen shoulder. Br J Rheumatol 1986;25:288-92.

4 Douglas WA. Treatment of idiopathic frozen shoulder with oral and intra-articular corticosteroids. Aust Musculoskeletal Med 2004:9:7.

5 Schaeffer B, Tibone JE, Kerian RK. Frozen shoulder - a long term follow-up. J Bone Joint Surg Am 1992;74:738-46.

\section{Author's reply}

I thank Dr Douglas for his interest and observations about our trial. He has documented his positive anecdotal experience in treating 30 patients with adhesive capsulitis with a combination of intra-articular and oral corticosteroids in a brief letter to the editor. ${ }^{1}$ Unfortunately, this has not been published as a full report so no details are provided. It is not clear whether this was an open prospective trial or a retrospective chart review, and, if the latter, whether all patients with adhesive capsulitis were included in the review. Similarly, no numerical data are provided and the time interval between the 1-2 intra-articular steroid injections and the start of oral prednisone was not reported. None the less, his claim that all patients fully recovered, on average 4.5 weeks from initiation of treatment (although no measure of variance is provided) is noteworthy, lends broad support to the conclusions of our trial, ${ }^{2}$ and, we agree, may warrant a formal trial.

We disagree that double blind trials pose a problem trial in studying adhesive capsulitis, as this is the best method for minimising bias in assessment of treatment outcome. Placebo controlled trials are appropriate when there are no known effective treatments, and controlled trials are essential for self limiting conditions such as adhesive capsulitis. While we agree that adhesive capsulitis is a painful, disabling condition, most studies have in fact established that it has a good prognosis, with resolution of symptoms in 2-3 years, on average, in the majority of patients.

We also disagree with the suggestion that potential trial participants should be excluded if symptoms have been present for longer than 16 weeks. Although we agree that corticosteroids may be more effective in the earlier phase of adhesive capsulitis, and therefore attempting to limit participation in trials of corticosteroids to those with recent onset of symptoms may appear to have merit, early recruitment has proved universally difficult for trialists in this field.

Furthermore, our positive trial, which included participants with an average of $21-$ 25 weeks of symptoms, provides clear evidence that this constraint is not necessary.

R Buchbinder

Department of Clinical Epidemiology Cabrini Hospital and Monash Department of Epidemiology and Preventive Medicine, Suite 41, Cabrini Medical Centre, 183 Wattletree Rd, Malvern, Victoria, Australia 3144; rachelle.buchbinder@med.monash.edu.au

\section{References}

1 Douglas WA. Treatment of idiopathic frozen shoulder with oral and intra-articula corticosteroids. Aust Musculoskeletal Med 2004;9:7

2 Buchbinder R, Hoving J, Green S, Forbes A, Hall S, Nash P. Short-course prednisolone therapy for the stiff painful shoulder (adhesive capsulitis or frozen shoulder): a randomised placebo-controlled trial. Ann Rheum Dis 2004;63:1460-9.

\section{CORRECTION}

doi: 10.1136/ard.2004.023564corr 1

Prevalence and pattern of radiographic hand osteoarthritis and association with pain and disability (the Rotterdam study) (Dahaghin S, Bierma-Zeinstra S M A, Ginai A Z, Pols H A P, Hazes J M W, Koes B W. Ann Rheum Dis 2005;64:682-7.)

Figure 3 in this article should have been published in colour but mistakenly appeared in black and white. The correct figure has now been inserted in the Online version and subscribers to the journal can see the amended article at http://ard.bmjjournals. com/cgi/content/full/64/5/682

\section{FORTHCOMING EVENTS}

\section{Second EULAR Course on Systemic Lupus Erythematosus}

4-9 September 2005; San Miniato, Italy

This course for 70 young rheumatologists (age <40) has been designed to provide comprehensive, intensive training on various aspects of this disease. It will deal with the following topics:

- Treatment of SLE, molecular basis of drug action, and pharmacogenetics

- Evaluation of patients with SLE: disease activity, damage, response to treatment

- Renal disease in SLE

- Neurological disease in SLE

- Skin disease in SLE

- Particular problems in SLE: fever, vaccination, pregnancy, haematological manifestations

Contact: Organising secretariat: c/o Clinical and Experimental Rheumatology, Via Santa Maria 31, I-56126 Pisa, Italy.

Tel.: +39-050-40124

Fax: +39-050-502299

Email: slecourse@clinexprheumatol.org

\section{Third International Conference on Neuroendocrine Immune Basis of the Rheumatic Diseases}

10-12 September 2005; Genova-Santa Margherits, Italy

Topic: The clinical translation of the neuroendocrine immune mechanisms of the rheumatic diseases for a better understanding and management of their diagnosis and treatment.

Local organiser: Professor Maurizio Cutolo, Division of Rheumatology, DIMI, University of Genova, Italy

Email: mcutolo@unige.it

Contact: Organising secretariat: Michela Civelli, EDRA spa, Viale Monza , 133 20125, Milan, Italy

Tel: $+39(0) 228172300$

Fax: +39 (0)2 28172399

Email:3rdnei@edraspa.it

\section{Mediterranean Congress of Rheumatology}

22-24 September 2005; Heraklion Crete, Greece

The meeting is organised by the Departments of Medicine, Rheumatology, and Clinical Immunology and Allergy, University of Crete.

Contact: Organising Bureau (secretariat and travel office) of the Mediterranean Congress of Rheumatology

Tel: 00302109006000

Fax: 00302109249836

Email: nickolopoulou@amphitrion.gr

\section{Future EULAR congresses}

21-24 June 2006; EULAR 2006; Amsterdam, The Netherlands

13-16 June 2007; EULAR 2007; Barcelona, Spain

11-14 June 2008; EULAR 2008; Paris, France 